\title{
Thorax computed tomography findings in patients victims of chest trauma
}

\section{Achados tomográficos em pacientes vítimas de trauma torácico}

Francisco Jose Rodrigues de Moura Filho' ${ }^{1}$ Marilza Oliveira ${ }^{2}$.

1 Médico, graduado em Medicina na Universidade Federal do Ceará (UFC), com Especialidade Médica em Radiologia e Diagnóstico por Imagem, Instituto Doutor Jose Frota (IJF), Fortaleza, Ceará, Brasil. 2 Médica, graduada em Medicina na Universidade Federal do Ceará (UFC), com Especialidade Médica em Radiologia e Diagnóstico por Imagem, Instituto Doutor Jose Frota (IJF), Fortaleza, Ceará, Brasil.

\begin{abstract}
Objective: To describe thorax computed tomography findings in patients assisted in the emergency unit of Institute Dr Jose Frota (IJF). Materials and Methods: Descriptive study analyzing 160 consecutive contrast-enhanced thorax computed tomography of patients victims of thoracic trauma admitted to the emergency unit of IJF, between November 1st, 2014 and January 31 st, 2015. Results: Abnormal findings were observed in $91,2 \%$ of the patients. Among them, the following findings were most frequently observed: fractures (48\%), hemothorax (43\%), atelectasis (37\%), pneumothorax $(26 \%)$ and lung contusions (17\%) Rupture of the esophagus was seen in three patients. Conclusion: We recognize that the findings encountered in our study are of similar prevalence to the ones reported in the literature and that CT scan is essencial to quickly diagnose these findings.
\end{abstract}

Keywords: Multidetector computed tomography. Thoracic injuries. Diagnostic imaging.

\section{RESUMO}

Objetivo: Descrever os achados tomográficos de pacientes submetidos à tomografia computadorizada de tórax atendidos no pronto-socorro do Instituto Dr Jose Frota (IJF). Materiais e Métodos: Estudo descritivo pela análise sequencial de 160 tomografias de tórax de pacientes vítimas de trauma torácico admitidos no pronto-socorro do IJF entre 1 de novembro de 2014 a 31 de janeiro de 2015, submetidos a tomografia computadorizada com a administração de contraste endovenoso. Resultados: Observou-se a presença de alterações em 91,2\% dos exames. Destas, as mais frequentes foram: fraturas (48\%), hemotórax (43\%), atelectasia (37\%), pneumotórax $(26 \%)$ e contusão pulmonar (17\%). Ruptura de esôfago foi encontrada em três pacientes. Conclusão: Reconhecemos que os achados encontrados em nosso estudo são de similar prevalência a de outros relatos descritos na literatura e que a tomografia computadorizada é essencial para prontamente diagnosticar esses achados.

Palavras-chave: Tomografia computadorizada multidetectores. Traumatismos torácicos. Diagnóstico por imagem.

Corresponding Author: Francisco Jose Rodrigues de Moura Filho, Rua Barão do Rio Branco 1816, Centro, Fortaleza, Ceará. CEP: $60025-061$. E-mail: drmouramd@yahoo.com

Conflict of interests: The authors have no conflicts of interest to declare.

Received: 14 Oct 2015; Revised: 28 Oct 2015; Accepted: 08 Dec 2015. 


\section{INTRODUCTION}

Thoracic injuries and its related complications are the third most common type of injuries found in trauma patients, increasing thus mortality and morbidity in trauma setting, and may evolve to lethality in up to $25 \%$ of cases. ${ }^{1,2}$ Motor vehicle collisions are the major source of blunt chest trauma representing approximately two thirds of the cases, next to falls and blows from blunt objects. ${ }^{3}$ Penetrating chest injuries are also relevant and may be categorized as being of low, medium or high velocity. Low-velocity injuries, such as knife wounds, are those that cause lesion only in the structures penetrated, whereas medium-velocity ones lead to greater primary tissue destruction, such as bullet wounds from most types of handguns, which is less extensive damage than the wounds caused by high-velocity forces originated from rifles and from military weapons. ${ }^{4}$

Imaging studies play an essential role of thoracic trauma care being an important tool in management of these chest trauma patients. ${ }^{5}$ Chest radiography has limitations regarding in detecting some findings and underestimates the severity and extent of chest trauma in some cases, thus the multidetector computed tomography (MDCT) has been increasingly used for trauma, because its speed and better ability of diagnose a variety of injuries and it may even demonstrate significant findings in patients with normal initial radiographs. ${ }^{6}$ Adequate technique is required including the use of intravenous iodinated contrast media.

In this article, we describe the characteristic MDCT findings of traumatic chest injuries found in patients admitted to the emergency unit of Institute Dr Jose Frota, the main emergency and trauma hospital of Ceará state, with radiologists available 24 hours per day. Injuries reported are those of the pleural space (hemothorax, pneumothorax), lungs (pulmonary contusion), esophagus (rupture of esophagus), heart (hemopericardium), aorta (aortic dissection), diaphragm and chest wall (rib fracture, scapule fracture, subcutaneous emphysema). It should be highlighted that multiple of these injuries may coexist in a single patient.

Because of the shortage of local scientific studies on the thorax trauma MDCT findings and considering the relevance of this issue, the present study was aimed at describing these findings in chest MDCT after trauma.

\section{MATERIALS AND METHODS}

A descriptive study was undertaken with sequential analysis of 160 thorax MDCT of patients admitted to the emergency unit of Institute Dr Jose Frota during three months, from November 1st, 2014 until January 31st, 2015.

The thorax MDCT that were selected in this study were those from patients admitted to the IJF's emergency unit during the mentioned period with chest trauma history, regardless of being a blunt or penetrating chest trauma, and that were submitted to thorax contrast-enhanced MDCT. Images obtained from CT scanning of these patients were analyzed by two radiologists at workstation, before and after the administration of intravenous contrast media.

The scans were performed with the patients in dorsal decubitus, in a 16-slice MDCT scanner Siemens Somatom Emotion, with a protocol that included intravenous administration of $1,5 \mathrm{~mL} / \mathrm{kg}$ of iodinated contrast medium at a flow rate of $4 \mathrm{~mL} / \mathrm{s}$, collimation of $1.25 \mathrm{~mm}$, tube voltage of $130 \mathrm{kVp}$ and a variable tube current time product (mAs).

We considered two types of findings: those directed related to chest trauma and other findings encountered not necessarily caused by the trauma.

\section{RESULTS}

In the sample of this study, 146 MDCT (91.2\%) presented alterations and only $14(8.8 \%)$ had results within the normality standards. The average age of the patients was 39 years, and 126 were male $(78.8 \%)$ and 34 female $(21.2 \%)$.

Of the 146 MDCT of patients with abnormal findings only $31(21.2 \%)$ had a single abnormality, having the others 115 (78.8\%) between 2 and 9 abnormal findings.

The most common finding encountered was fracture seen in almost $50 \%$ of the patients (Table 1), being the most common location of fracture in the ribs (Graphic 1).

Penetrating trauma occurred in 23 patients (14\%), due to bullet wounds reported as metal densities located either in chest wall or lung parenchyma.

Other MDCT findings encountered that may be either related to complications of other thoracic trauma injuries or preexisting comorbidities are shown in Table 2.

\section{DISCUSSION}

In our study the majority of thorax MDCT ( $>90 \%)$ from patients victim of chest trauma had abnormal findings on MDCT scan.

Rib fracture is the most common skeletal injury in blunt chest trauma. ${ }^{7}$ We encountered this finding in 42 patients (26\%) which corresponds to $54 \%$ of all fractures observed. Although fractures of the scapula are uncommon, occurring in about $4 \%$ of patients with multiple injuries ${ }^{8}$ this was the second most common type of fracture, being observed in 16 patients $(10 \%)$. Significant force is necessary to fracture the scapula which commonly is seen in motor vehicle collisions and in falls from great heights, being the first one mentioned the leading cause in our patients ${ }^{7}$. Others fractures found were vertebral fractures of the thoracic spine, sternal fracture, clavicle fracture and humerus fracture seen in 9, 6, 4 and 1 patient(s), respectively.

Hemothorax, the second most common finding observed in 69 patients $(43 \%)$, is the presence of blood in the pleural space, 
which may originate from injuries involving the lung, chest wall, heart, great vessels or abdominal injuries. Measurement of pleural fluid attenuation was taken in all exams of the patients with pleural effusion being considered hemothorax in those with values between 35-70 HU.

Atelectasis, a condition in which one or more areas of the lungs collapse or don't inflate properly, was found in 60 patients (37\%). This finding was prevalent in those patients with rib fracture possibly due to the limited respiratory movement that may lead to an increased prevalence of atelectasis and subsequent pneumonia. ${ }^{9}$ Consolidation was found in 28 patients (17\%). Furthermore, blood in the pleural space (hemothorax) can compress the underlying lung and cause atelectasis also.

Table 1. Findings related to chest trauma

\begin{tabular}{|c|c|c|}
\hline & $\mathrm{n}$ & $\%$ \\
\hline Fracture & 78 & 48,8 \\
\hline Hemothorax & 69 & 43,1 \\
\hline Atelectasis & 60 & 37,5 \\
\hline Pneumothorax & 42 & 26,2 \\
\hline Lung Contusion & 28 & 17,5 \\
\hline Subcutaneous emphysema & 27 & 16,8 \\
\hline Metal density in thorax & 23 & 14,3 \\
\hline Mediastinal shift & 18 & 11,2 \\
\hline Hidropneumothorax & 13 & 8,1 \\
\hline Hemopericardium & 8 & 5 \\
\hline Pneumomediastinum & 8 & 5 \\
\hline Injury of diaphragm & 4 & 2,4 \\
\hline Condroesternal dislocation & 3 & 0,6 \\
\hline Rupture of esophagus & 3 & 0,6 \\
\hline Aortic dissecation & 3 & 0,6 \\
\hline
\end{tabular}

$\mathrm{n}=$ number of patients of the sample with the finding. $\%=$ percentage of the finding within the sample analysed.
Graphic 1. Distribution of fractures

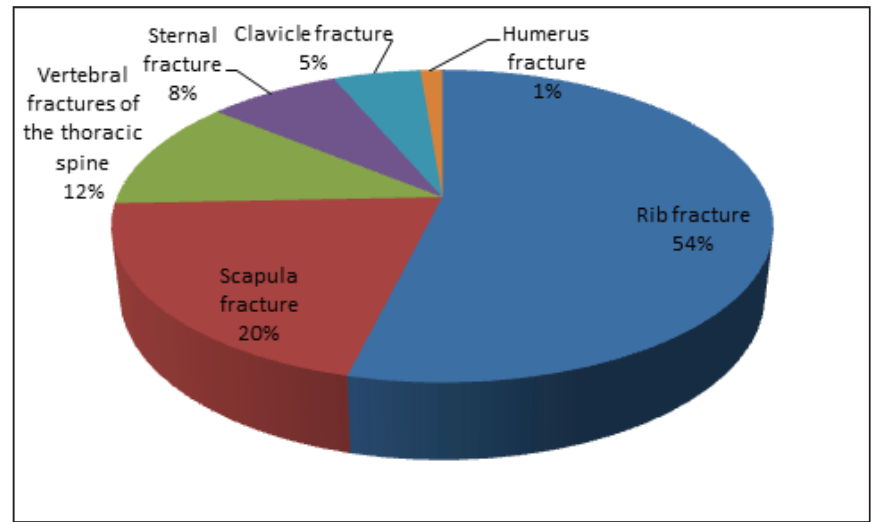

Table 2. Other findings observed

\begin{tabular}{|c|c|c|}
\hline & $\mathrm{n}$ & $\%$ \\
\hline Consolidation & 28 & 17,5 \\
\hline Bullous emphysema & 13 & 8,1 \\
\hline Pleural effusion & 12 & 7,5 \\
\hline Lung nodule & 11 & 6,9 \\
\hline Ground glass opacity & 9 & 5,6 \\
\hline Pulmonary fibrosis & 6 & 3,7 \\
\hline Pulmonary cysts & 5 & 3,1 \\
\hline Bronchiectasis & 5 & 3,1 \\
\hline Pleural thickening & 4 & 2,4 \\
\hline Pleural empyema & 4 & 2,4 \\
\hline Interlobular septal thickening & 2 & 1,2 \\
\hline Lung abscess & 2 & 1,2 \\
\hline Tree-in-bud opacity & 1 & 0,6 \\
\hline Pulmonary metastatic implants & 1 & 0,6 \\
\hline Accentuation of the pulmonary vascular markings & 1 & 0,6 \\
\hline Mediastinal lymphadenomegaly & 1 & 0,6 \\
\hline
\end{tabular}

$\mathrm{n}=$ number of patients of the sample with the finding. $\%=$ percentage of the finding within the sample analysed. 
Pneumothorax is an abnormal collection of air or gas in the pleural space that causes an uncoupling of the lung from the chest wall, is a very common traumatic condition that is seen in $15 \%-40 \%$ of all blunt chest trauma patients. ${ }^{10,11,12}$ In our study pneumothorax was found in 42 patients $(26 \%)$ (Figure 1), thus in accordance with the literature. Mediastinal shift was observed in 18 patients $(11 \%)$. Although tension pneumothorax is a clinical diagnose it may be suggested at imaging when some signs are present in addition to the pneumothorax, such as mediastinal shift to the contralateral side.

We found pulmonary contusion in 28 patients (17\%) (Figure 2 ). It is the most common lung injury from blunt chest trauma, with a prevalence of $17 \%-70 \% \cdot{ }^{13,14}$ It is a focal parenchymal injury of the alveolar epithelium, with interstitial edema and alveolar hemorrhage, but without significant alveolar disruption. ${ }^{15,16}$ Patients who have pulmonary contusion are at increased risk for developing pneumonia and respiratory distress syndrome.

Rupture of the esophagus was found in 3 patients (2\%) (Figure s $3 \mathrm{~A}, \mathrm{~B}$ and $\mathrm{C}$ ). Although blunt trauma to the esophagus is

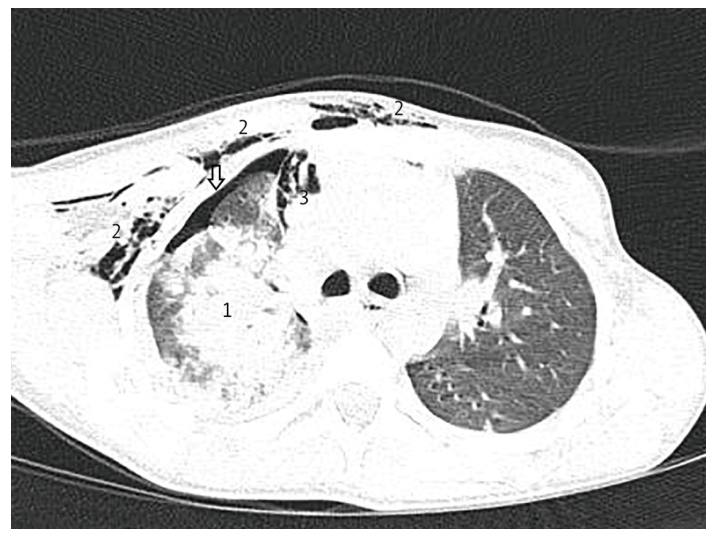

Figure 1. Pneumothorax (arrow) is illustrated in this contrastenhanced axial CT image of a 7-year-old child victim of blunt trauma. An extensive area of lung contusion in the right lung (1), subcutaneous emphysema (2) and pneumomediastinum (3) are also shown.

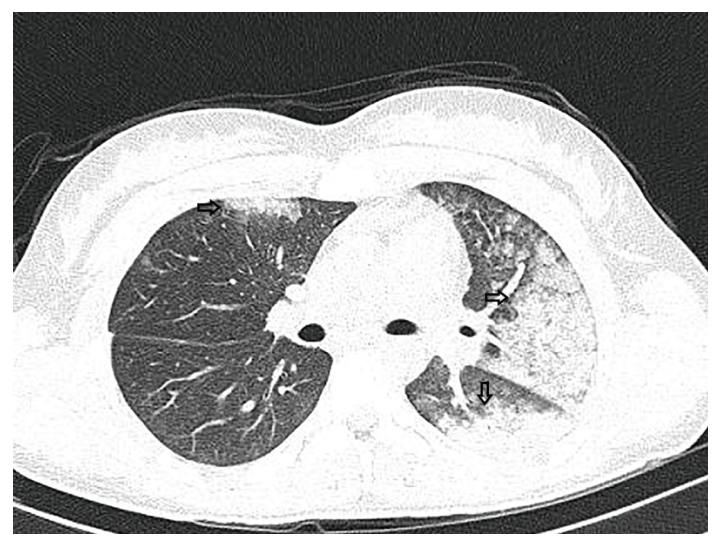

Figure 2. Bilateral areas of lung contusion (arrows), presenting as patchy opacities with thin subpleural sparing, more extensive in the left lung, are shown in this contrast-enhanced axial CT image of a 17 -year-old adolescent victim of blunt trauma. rare due to its position in the mediastinum, ${ }^{1}$ in our study this injury was found in patients who were victims of blunt trauma and not penetrating trauma. Pneumomediastinum, a MDCT finding that may suggest the diagnosis of traumatic esophageal perforation, was encountered in these patients. The same prevalence $(2 \%)$ was found for aortic dissecation. Aortic dissection, which is relatively uncommon, is a serious condition in which the inner layer of the aorta tears. Blood surges through the tear, causing the inner and middle layers of the aorta to separate (dissect).

Blunt injuries to the diaphragm are uncommon, with a prevalence of $0.16 \%-5 \%$ in blunt trauma patients ${ }^{17,18}$ and they develop by a sudden increase in intraabdominal or intrathoracic pressure against a fixed diaphragm. In our study we had this finding in 4 patients $(2,4 \%)$.

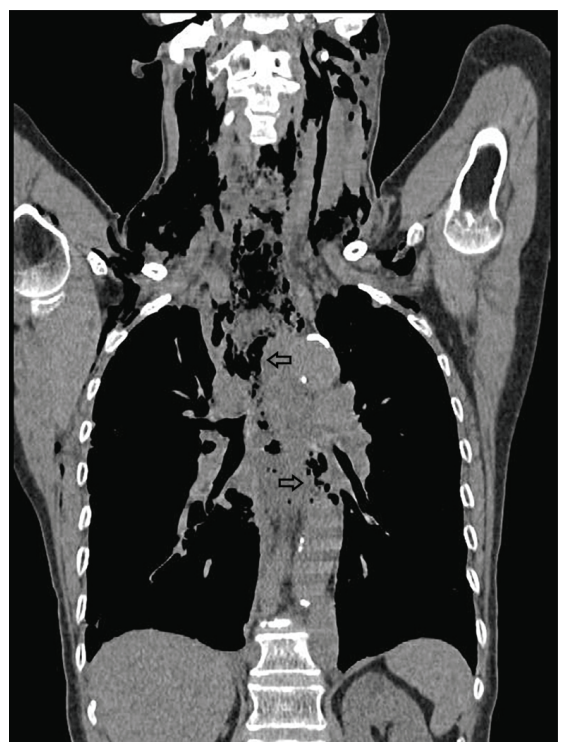

Figure 3 (A). Extensive pneumomediastinum (arrows) is shown in this coronal non-contrast CT image of a 74-year-old woman with rupture of the esophagus victim of blunt trauma.

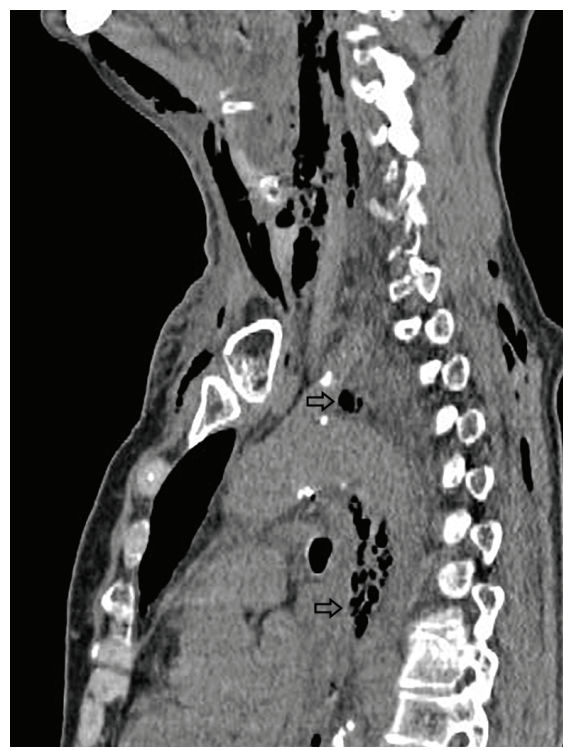

Figure 3 (B). Extensive pneumomediastinum (arrows) is shown in this sagital non-contrast CT image of a 74-year-old woman with rupture of the esophagus victim of blunt trauma. 


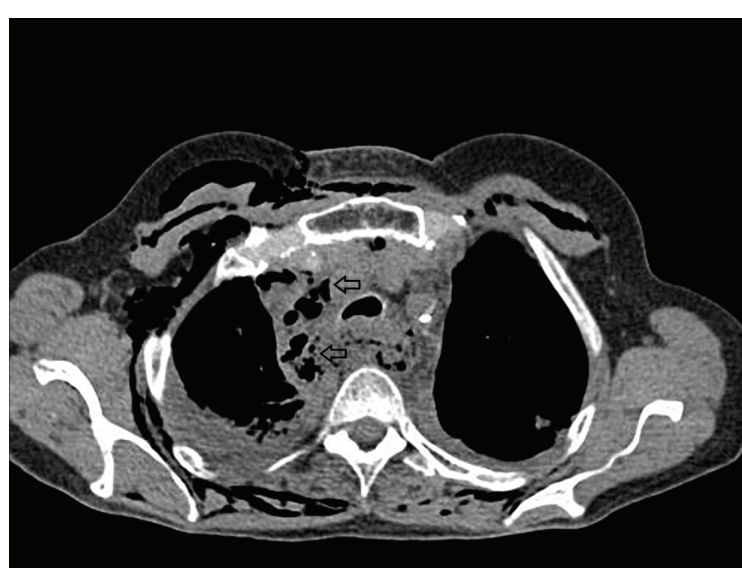

Figure 3 (C). Extensive pneumomediastinum (arrows) is shown in this axial non-contrast $\mathrm{CT}$ image of a 74-year-old woman with rupture of the esophagus victim of blunt trauma.

\section{REFERENCES}

1. Palas J, Matos AP, Mascarenhas V, Herédia V, Ramalho M. Multidetector computer tomography: evaluation of blunt chest trauma in adults. Radiol Res Pract. 2014;2014:1-12.

2. Clark DE, Fantus RJ. National trauma data bank: annual report 2007 [Internet]. The American College of Surgeons Committee on Trauma Leadership. Versão 7.0. Chicago: American College of Surgeons; 2007 [acesso 2015 mar 02]. 64p. Disponível em: https:// www.facs.org/ /media/files/quality\%20 programs/trauma/ntdb/ ntdbannualreport2007.ashx

3. Mirka H, Ferda J, Baxa J. Multidetector computed tomography of chest trauma: indications, technique and interpretation. Insights Imaging. 2012;3(5):433-49.

4. Shahani R, Galla JD, Talavera F, Schwartz DS, Milliken JC. Penetrating chest trauma [Internet]. New York: Medscape; 2007 [acesso 2015 mar 02]. Disponível em: http://emedicine.medscape. com/article/425698-overview\#a0102

5. Scaglione M, Pinto A, Pedrosa I, Sparano A, Romano L. Multidetector row computed tomography and blunt chest trauma. Eur J Radiol. 2008;65(3):377-88.

6. Exadaktylos AK, Sclabas G, Schmid SW, Schaller B, Zimmermann $\mathrm{H}$. Do we really need routine computed tomographic scanning in the primary evaluation of blunt chest trauma in patients with "normal" chest radiograph? J Trauma. 2001;51(6):1173-6.

7. Kaewlai R, Avery LL, Asrani AV, Novelline RA. Multidetector CT of blunt thoracic trauma. Radiographics. 2008;28(6):1555-70.

8. Weening B, Walton C, Cole PA, Alanezi K, Hanson BP, Bhandari M. Lower mortality in patients with scapular fractures. J Trauma. 2005;59(6):1477-81.
As previously mentioned, Table 2 listed other findings encountered, some of them such as pulmonary metastatic implants and lung nodules were preexisting findings not related to chest trauma. Others such as pneumonia/consolidation may either be preexisting findings or to have been developed as a consequence of the others injuries caused by the trauma.

\section{CONCLUSION}

In the present study, the most common contrast-enhanced chest MDCT findings in emergency trauma settings encountered were similar to those observed in other studies previous reported. Multidetector computed tomography scan plays an important role in trauma setting once it can quickly and accurately diagnose these thoracic injuries described in our study.

9. Barnea Y, Kashtan H, Skornick Y, Werbin N. Isolated rib fractures in elderly patients: mortality and morbidity. Can J Surg. 2002;45(1):43-6.

10. Moore EE, Feliciano DV, Mattox KL, editores. Trauma. 7. ed. New-York: McGraw-Hill Education; 2013. Capítulo 25, Lung, trachea, and esophagus; p. 468-84.

11. Mayberry JC. Imaging in thoracic trauma: the trauma surgeon's perspective. J Thorac Imaging. 2000;15(2):76-86.

12. Miller LA. Chest wall, lung, and pleural space trauma. Radiol Clin North Am. 2006;44(2):213-24.

13. Wagner RB, Crawford WO Jr, Schimpf PP. Classification of parenchymal injuries of the lung. Radiology. 1988;167(1):77-82.

14. Cohn SM. Pulmonary contusion: review of the clinical entity. J Trauma. 1997;42(5):973-9.

15. Mullinix AJ, Foley WD. Multidetector computed tomography and blunt thoracoabdominal trauma. J Comput Assist Tomogr. 2004;28 Supl 1: S20-7.

16. Oikonomou A, Prassopoulos P. CT imaging of blunt chest trauma. Insights Imaging. 2011;2(3):281-95.

17. Sliker CW. Imaging of diaphragmatic injuries. Radiol Clin North Am. 2006;44:199-211.

18. Mirvis SE, Shanmuganagthan K. Imaging hemidiaphragmatic injury. Eur Radiol. 2007;17(6):1411-21.

Como citar:

Moura FJ Filho, Oliveira M. Thorax computed tomography findings in patients victims of chest trauma. Rev Med UFC. 2015 jul-dez;55(2):28-32. 